Digilec 7 (2020), pp. 11-28

Fecha de recepción: 21/10/2020

Fecha de aceptación: 28/12/2020

DOI: https://doi.org/10.17979/digilec.2020.7.0.7074

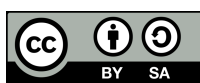

e-ISSN: 2386-6691

\title{
HACIA UNA MAYOR AUTONOMÍA EN LA CONSTRUCCIÓN DE IDENTIDADES DE GÉNERO PARTIENDO DE LA MIRADA CRÍTICA DE MERNISSI Y EL HACHMI
}

\author{
TOWARDS GREATER AUTONOMY IN THE CONSTRUCTION OF \\ GENDER IDENTITIES FROM THE CRITICAL VIEWPOINT OF \\ MERNISSI AND EL HACHMI
}

\author{
Patricia MARTÍNEZ-LEÓN* \\ Universitat de València \\ Orcid: https://orcid.org/0000-0002-7269-5505
}

\begin{abstract}
Resumen
En este trabajo destacamos dos problemas en la construcción de identidades de género por parte del alumnado adolescente: la escasa incorporación de contribuciones culturales femeninas en manuales escolares y cánones literarios, y la imagen distorsionada de las mujeres de origen marroquí instaurada en el imaginario colectivo, que oculta sus manifestaciones de autonomía y perjudica las relaciones interculturales. Nuestro objetivo fundamental es realizar un análisis discursivo de cuatro títulos de Fatema Mernissi y Najat El Hachmi en relación a la identidad de género para establecer las claves del modelo subyacente y valorar, a continuación, las posibilidades de explotación didáctica de este pequeño corpus en la etapa de Educación Secundaria, centrándonos, en particular, en las oportunidades que ofrece para contribuir a contrarrestar esa imagen distorsionada de las mujeres de origen marroquí a la que nos referíamos. Previamente, en el marco teórico, abordamos los conceptos de género e identidad de género, la representación de las mujeres inmigrantes de origen marroquí en el imaginario colectivo europeo y algunas investigaciones disponibles sobre la ausencia de aportaciones culturales femeninas en los manuales de Educación Secundaria y sus consecuencias.
\end{abstract}

Palabras clave: Enseñanza secundaria; literatura; feminismo; rol de los géneros

\begin{abstract}
In this study we highlight two problems in the construction of gender identities by adolescent students: the scarce incorporation of female cultural contributions in school texts and literary canons, and the distorted image of women of Moroccan origin in the collective imagination, which conceals examples of autonomy and damages intercultural relations. Our objective is to make a discursive analysis of four titles by Fatema Mernissi and Najat El Hachmi regarding gender identity in order to establish the key elements of

* Universitat de València. Facultat de Magisteri. Departament de Didàctica de la Llengua i la Literatura. Avda. dels Tarongers, 4. Valencia. Email: patricia.martinez-leon@uv.es
\end{abstract}


their underlying model. We then assess the possibilities of using this small corpus in secondary education, focusing on the opportunities it offers to help counteract the distorted image of women of Moroccan origin mentioned before. In the theoretical framework, we address the concepts of gender and gender identity, the representation of immigrant women of Moroccan origin in the European collective imaginary, and some available research on the lack of female cultural contributions in secondary school textbooks and its consequences.

Key Words: Secondary Education; Literature; Feminism; Gender roles 


\section{INTRODUCCIÓN Y OBJETIVOS}

Las relaciones asimétricas de poder entre hombres y mujeres constituyen uno de los principales problemas en los procesos de construcción de identidades de género. Pero a menudo reconocemos la expresión de formas de desigualdad de género en países árabes o entre personas originarias de estos, al tiempo que nos resistimos a identificarlas en las sociedades occidentales. Esta mirada sesgada entorpece las relaciones interculturales, además de contribuir a difundir una imagen bastante desajustada en el caso concreto de las mujeres originarias de Marruecos.

Como sostiene Nash (2001), cuando tanto la categoría de género como la cultural están marcadas con la etiqueta de la alteridad proliferan los estereotipos en las representaciones identitarias realizadas, que se instalan en el imaginario colectivo y con las que nos movemos a menudo pese a que sean distorsionadas. Este es el caso de las mujeres de origen marroquí, representadas en discursos basados en un modelo de dependencia y marginación, analfabetismo y sumisión, que defendemos que han de ser desmontados si tenemos interés en mejorar la convivencia entre culturas en contacto en las sociedades actuales.

Como apuntan García et al. (2011: 289):

Por oposición a Occidente las mujeres del llamado “tercer mundo", en particular las musulmanas, también han sido asociadas a la ignorancia, al fervor religioso irracional y al atraso social. En su mayor parte, han sido claramente caracterizadas como víctimas irrevocablemente sometidas a las disciplinas patriarcales propias de su cultura (Mohanty; Russo, 1991). De esta forma, las procedencias alterizadas han sido presentadas como sociedades a las que se corresponden unas relaciones de poder inmutablemente discriminatorias con respecto al género femenino (Ahmed, 1992) [...] La mujer musulmana se representa pues como víctima de una tragedia que la perseguirá desde su nacimiento. La sumisión femenina y reclusión domestica atribuidas a las mujeres orientales musulmanas conforma el conjunto semiótico que se asocia a la religión islámica y al velo como signo de exteriorización de la diferencia cultural. Esta visión religioso-culturalista tendría según Benhabib (2002) un efecto perverso, ya que cuestionar los comportamientos de estas mujeres desde la perspectiva cultural las dejaría prisioneras del patriarcado del que intentan escapar.

Teniendo en cuenta, por otra parte, la especial incidencia de la Educación Secundaria Obligatoria en los procesos de construcción identitaria, en la medida en que se aportan referentes, esquemas y patrones sociales a todas las personas en un tiempo vital en el que tales procesos adquieren un énfasis especial, preocupa la escasa presencia de referentes de mujeres que se detecta en los manuales dirigidos a esta etapa, así como su omisión de los cánones literarios, que sirve de sustrato a un orden social discriminatorio, privando a las alumnas de modelos de realización intelectual para la identificación (López-Navajas, 2012 y 2014; López-Navajas y López García-Molins, 2012).

Sobre la base de las preocupaciones anteriores, el objetivo fundamental de este trabajo es realizar un análisis discursivo de cuatro títulos de Fatema Mernissi y Najat El Hachmi en relación a la identidad de género para establecer las claves del modelo subyacente y valorar, a continuación, las posibilidades de explotación didáctica de este pequeño corpus en la etapa de Educación Secundaria, centrándonos, en particular, en las 
oportunidades que ofrece para contribuir a contrarrestar la imagen distorsionada de las mujeres de origen marroquí instaurada en el imaginario colectivo.

Se trata en los dos casos de autoras nacidas en Marruecos que hemos considerado interesantes por la implicación que muestran en su escritura con la conquista de autonomía por parte de las mujeres en la construcción de su identidad de género. Las obras escogidas son Sueños en el umbral, de Fatema Mernissi, y El último patriarca, La hija extranjera y Jo també sóc catalana, de Najat El Hachmi, coincidentes en las siguientes características: son protagonizadas por mujeres de origen marroquí, se enmarcan en el terreno entre la ficción autobiográfica y las memorias, son ricas en los modelos de mujer representados y describen con detalle la complejidad y las sucesivas fases en la conquista de esa autonomía objeto de nuestro interés.

\section{MARCO TEÓRICO}

La identidad de género se define como la identificación de cada cual en tanto hombre o mujer o la categorización en tránsito entre estas opciones y la interpretación personal realizada del significado de estas categorías que, en la medida en que son construcciones socioculturales, pueden ser llenadas de diferentes contenidos (Carro, Barbé i Serra y Vidal, 2014). La construcción social de la diferencia sexual se realiza a través de representaciones de la misma que trasladan una serie de características, pautas de conducta y valores presentados como normativos. Cuando esa diferencia construida entre las categorías de género se naturaliza se establece una jerarquía en torno a una oposición binaria en términos de superioridad/inferioridad entre hombres y mujeres, que ha convertido a las segundas en la alteridad inferiorizada, negándoles la condición de sujetos y justificando su subordinación (Nash, 2001).

El elemento que mayor interés merece de la definición anterior es la idea de que las categorías de género son construcciones socioculturales a las que, por consiguiente, cada individuo en cada contexto puede atribuir un significado distinto, desarrollando su propia manera de pensar y de actuar en consecuencia. En otras palabras, no existen modelos, atributos, actos o significados de género correctos o incorrectos, sino que el género de cada persona va conformándose a través de las propias acciones y de la atribución personal de significados en el diálogo o mediante la transgresión de los establecidos como normativos. En palabras de Butler (2006: 70): “El género es el mecanismo a través del cual se producen y se naturalizan las nociones de lo masculino y lo femenino, pero el género bien podría ser el aparato a través del cual dichos términos se deconstruyen y se desnaturalizan”. En otro momento esta misma autora (Butler, 2010: 39) se expresa con gran claridad sobre la construcción cultural del género:

Si el género es los significados culturales que asume el cuerpo sexuado, entonces no puede decirse que un género sea resultado de un sexo de manera única. Llevada hasta su límite lógico, la distinción sexo/género indica una discontinuidad radical entre cuerpos sexuados y géneros culturalmente construidos.

Y sobre la intersección del género con otras categorías (Butler, 2010: 35), especialmente relevante en este trabajo, manifiesta: 
Si una es una mujer, desde luego eso no es todo lo que una es; el concepto no es exhaustivo, no porque una "persona" con un género predeterminado trascienda los atributos específicos de su género, sino porque el género no siempre se establece de manera coherente o consistente en contextos históricos distintos, y porque se interseca con modalidades raciales, de clase, étnicas, sexuales y regionales de identidades discursivamente constituidas. Así, resulta imposible desligar el "género" de las intersecciones políticas y culturales en que invariablemente se produce y se mantiene.

Consideramos que un desarrollo relativamente confortable de quiénes somos, en cualquiera de las dimensiones que integra nuestra identidad, es alcanzado cuando conquistamos un mayor grado de autonomía en su construcción. Concretamente en el plano del género, defendemos las múltiples posibilidades de identificación y de expresión que atraviesan las categorías establecidas como normativas o que entran en contradicción con los significados rígidos impuestos.

\subsection{Construcción de identidades de género en la escritura de autoras magrebíes: Mernissi y El Hachmi}

La escritura de autoras magrebíes reúne características de especial interés para nuestro estudio. La lectura de autoras como Bueno (2009) y Segarra (1998), que las describen, permite centrar la mirada durante la lectura de los textos escogidos. Señalan que se trata de una escritura en primera persona, entre la ficción autobiográfica y las memorias, en la que confluyen el desarrollo de la identidad de género y de los sentimientos de pertenencia cultural, que plasma un proceso de construcción identitaria dinamizado a través de la palabra y el pensamiento y definido por la complejidad y la contradicción. Se detienen en el desarrollo de modelos y roles de género y en la incidencia de la tradición y la cultura en el comportamiento de las mujeres, denuncian su opresión y discriminación y destacan la contribución de la lectura y la escritura a la liberación de estas. Además, el desarrollo de una voz individual se conjuga con un compromiso colectivo, en un ejercicio de escritura entendido como una doble provocación, en la medida en que, de una parte, supone la toma de palabra y contribuye al desarrollo de la autonomía de la mujer y a su introducción en el espacio público y de otra, es una expresión de individualidad valorada negativamente en la cultura musulmana.

Nosotros nos decantamos en esta ocasión por la escritura de Fatema Mernissi y Najat El Hachmi, de cuyo pensamiento resaltamos algunas ideas fundamentales a continuación. Mernissi $(1991,1995)$ insiste en que el modelo de género impuesto a las mujeres en algunos países árabes, basado en la sumisión y que limita la posibilidad de dirigir sus vidas, responde a una estrategia política de ataque a la democracia que pretende anular la participación ciudadana de la mitad de la población. El problema es la lectura parcial e intencionada de los textos religiosos, centrada en un modelo medieval de mujer, que se emplea como justificación para perpetuarlo. También destaca la tendencia progresista en cuanto a la situación de la mujer y sus derechos en muchos países árabes y apunta algunas vías para dotar de continuidad a la mejora, como la alfabetización y la construcción activa por parte de las mujeres de imágenes e ideas propias a través de la literatura y del cine. Del pensamiento de Najat El Hachmi (2008) destacaremos la 
ejemplificación de situaciones de opresión de la mujer tanto en el mundo árabe como en las sociedades occidentales y el cuestionamiento crítico que realiza al supuesto modelo de emancipación y liberación femenina en las segundas, ilustrando las múltiples ocupaciones y los cánones de belleza a los que, de alguna manera, también se someten en Occidente las mujeres.

\subsection{La representación de las mujeres inmigrantes de origen marroquí en el imaginario colectivo europeo}

García et al. (2011) se refieren a las claras connotaciones de género manifiestas en el conflicto cultural entre el Occidente moderno y un Islam orientalizado y obsoleto y a la conversión de la mujer musulmana en uno de los elementos de diferenciación cultural fundamentales. En este sentido, ahondan en el papel atribuido al género en la construcción de la diferencia, pues se representa a Oriente como una serie de culturas y civilizaciones que someten a las mujeres y se utiliza esta característica para delimitar la frontera entre las identidades occidentales y orientales. Otra cuestión interesante de su estudio se halla en el acceso que posibilita a la percepción de las propias mujeres musulmanas, tan conscientes de los estereotipos construidos sobre sí mismas (es decir, del carácter socialmente construido del estereotipo femenino oriental) como de la distancia entre estos y sus experiencias personales reales.

Sería un error homogeneizar la imagen de la mujer inmigrante de origen marroquí residente en España. En este sentido, Ramírez (1996) propone una clasificación de las mujeres marroquíes que llegan a España, diferenciando tres grupos: las vinculadas previamente a una situación familiar de procreación (con origen en la inmigración familiar y de extracción social generalmente similar a la del marido), el grupo de solteras, pero vinculadas a la red de parentesco de la primera clasificación (familiares de alguien ya residente en España que llegan mediante la reagrupación familiar) y otro grupo de mujeres con cierta cualificación, solteras y con mentalidad y prácticas más occidentalizadas (que llegan a través de amigas y para las que el trabajo supone la independencia económica y la liberación de la tutela masculina). Es en el tercer grupo de esta clasificación en el que la conquista gradual de autonomía generalmente alcanzaría cotas más altas, si bien en los tres casos con la llegada a España se realiza la socialización bajo nuevas pautas culturales, en un ejercicio en el que se conjugan el mantenimiento del sentimiento de pertenencia a la comunidad cultural de origen y el desarrollo de un nuevo sentido de pertenencia a la sociedad de acogida. En este sentido, son diversos los autores que se refieren a la conciliación de identificaciones o pertenencias plurales (MartínezLeón, Ballester-Roca e Ibarra Rius, 2017; Tellez, 2011).

Más allá de lo anterior, como sostienen García et al. (2011: 287-288), no podemos pasar por alto que:

Los medios de comunicación juegan un papel protagonista en la vehiculización de las imágenes sobre los colectivos inmigrados y en particular sobre sus mujeres. Si bien estas "inmigrantes" se encuentran infra-representadas en los medios, en los pocos casos en los que aparecen, lo hacen como portadoras de los estereotipos más recurrentes sobre sus culturas de origen, lo que las convierte en símbolos de su comunidad de origen (Nash, 2003). Así se define una comunidad imaginada de 
mujeres "inmigrantes", que las aglutina en un grupo homogéneo y sirve para alimentar creencias colectivas a través de las que se articulan las pautas de inclusión y exclusión social (...) El rechazo a "lo musulmán” se vehicula pues en gran medida a través de la mujer, considerada como víctima, no de un patriarcado, sino de su religión, y representada como el arquetipo de la mujer oprimida, lo cual la condena a una representación estereotipada. Cuando en Occidente se habla de la supuesta discriminación de las mujeres musulmanas, se obvian los verdaderos orígenes de esta situación, "se da por sentado que su religión es el origen de sus males, en vez de buscar las causas en la política de los Estados correspondientes y la herencia sociocultural patriarcal de sus sociedades” (Moualhi, 2000: 292).

Por último, a manera de contraste con la situación y representación de las mujeres inmigradas, nos referiremos a la investigación de Soriano y Santos (2002) sobre la situación social de las mujeres marroquíes en el país de origen, que da cuenta de un acceso al ámbito público por parte de estas que no sería equiparable al de los varones. Como contraparte, también se refieren a una evolución de la sociedad marroquí que se refleja en el acceso de las mujeres al ámbito educativo y en el intento por parte de estas de demostrar que su papel no se limita a la procreación e incluye la participación en las actividades económicas, en un ejercicio de búsqueda de independencia. Si bien esa participación se encontraría con resistencias por el estatuto jurídico de la mujer, por la limitación de determinados derechos legales y económicos y por el obstáculo en cuanto a la incorporación al mundo laboral en que puede convertirse el matrimonio.

Finalmente, concluyen que se puede hablar de una conquista paulatina de autonomía por parte de las mujeres marroquíes (retraso de la edad de matrimonio, mayor participación en el ámbito económico...) y llaman la atención sobre la idea (de especial interés para el objeto de esta investigación) de que en el proceso migratorio la mujer gana autonomía, poder y libertad y ensancha su esfera de influencia.

\subsection{La ausencia de mujeres en los manuales de Educación Secundaria, el desconocimiento de la tradición literaria femenina}

En este apartado realizaremos un breve repaso por algunos de los estudios de López-Navajas (2012, 2014) y López-Navajas y López García-Molins (2012) sobre la ausencia de las mujeres en los manuales de Educación Secundaria, el desconocimiento de la tradición literaria femenina y sus consecuencias, en la medida en que justifican la detección de una parte de la problemática que subyace al origen de nuestro trabajo.

El primero de los estudios (López-Navajas, 2012) se basa en el análisis de 115 manuales de tres editoriales de las 19 asignaturas de los cuatro cursos de ESO. Se trata de un análisis cuantitativo y cualitativo de la presencia y relevancia de mujeres y hombres en libros de texto de 2007, que revela la infrarrepresentación de las mujeres (suponen un 12,8\%), lo que comporta una casi total exclusión de la visión del mundo trasladada en el ámbito educativo y supone la ausencia de referentes de realización intelectual para las mujeres y la pérdida de acervo cultural para todos. Ello redunda en una falta de rigor académico y comporta además como consecuencia un déficit en la formación ciudadana de los estudiantes, condicionando su socialización.

Entre las conclusiones se obtiene una presencia muy baja de las mujeres en todas las asignaturas, que disminuye, además, a medida que los cursos aumentan de nivel y 
ganan en profundidad. La ausencia se acentúa en asignaturas y bloques de contenido histórico, que son las que construyen la memoria cultural y las identidades sociales. Es destacable el hecho de que la ausencia de la mujer sea la norma también en la narración de la contemporaneidad. En suma, todo ello evidencia una ocultación de las mujeres del relato histórico y la falta de autoridad social que se les concede, con la consiguiente orfandad en cuanto a referencias históricas, culturales y sociales de las mujeres y la contribución a un orden social excluyente.

Con la finalidad de corregir y subsanar la escasa presencia de las mujeres en los manuales de ESO de Lengua y Literatura se presenta una propuesta de inclusión de escritoras (López-Navajas, 2014), siempre introducidas en relación a las circunstancias históricas y sociales que las rodean, como pertenecientes a un movimiento artístico, como coetáneas o en relación a los conceptos y géneros trabajados, pero nunca de manera aislada. En este trabajo se enmarca a las autoras, se aporta información sobre ellas y se proponen una serie de actividades que responden al desarrollo de contenidos incluidos en el currículum de Educación Secundaria. Concretamente, se plantea una propuesta a partir de dos dramaturgas, Sor Juana Inés de la Cruz y Elena Garro, y se proponen una serie de actividades que se pueden incluir en diversos temas de Lengua y Literatura de segundo, tercero y cuarto de ESO.

El tercer estudio al que nos referiremos (López-Navajas y López García-Molins, 2012) habla sobre una falta de autoridad social asentada en el desconocimiento de las contribuciones de las mujeres a lo largo de la historia a la cultura. En este sentido, muestra la escasa presencia de las escritoras en el canon literario de los manuales de Educación Secundaria, lo que supone su exclusión de los referentes literarios y culturales y redunda en la falta de autoridad social de las mujeres y en sus dificultades para acceder a espacios de poder. En el estudio se realiza un recorrido por la silenciada tradición literaria femenina, aportando nombres de escritoras españolas pertenecientes a todas las épocas. Posteriormente, se hace un análisis del canon literario que presentan los manuales de Literatura de la ESO, resultante del estudio de los bloques de educación literaria de tercero y cuarto en los libros de texto de castellano, centrando la atención en los escritores y escritoras citados o reseñados. Se obtiene que en tercero de ESO el porcentaje de presencia femenina supone un 6\%, lo que se corresponde con 17 mujeres con respecto a 282 hombres, y en cuarto de ESO un 9,34\%, o 38 mujeres frente a 265 hombres.

\section{METODOLOGÍA Y RESULTADOS DE LA INVESTIGACIÓN}

\subsection{Metodología de la investigación}

En este trabajo partimos de la conceptualización de la investigación educativa realizada por Gimeno Sacristán (1989), que alude al análisis, la actuación y la discusión sobre la realidad educativa para un conocimiento más profundo y para su mejora. Esta mejora pasa por la identificación de preocupaciones (en nuestro caso, la imagen distorsionada de las mujeres de origen marroquí instalada en el imaginario colectivo y la 
escasa presencia de escritoras en el canon literario de Educación Secundaria) como punto de partida para el diseño de materiales con el propósito de darles respuesta.

Siguiendo a este mismo autor, nos acogemos al paradigma de investigación cualitativa, pues son de esta naturaleza los matices a los que prestamos atención en los datos objeto de análisis (el contenido de las cuatro novelas seleccionadas), porque consideramos que la comprensión de los modelos de género subyacentes demanda esta aproximación necesariamente cualitativa y porque somos conscientes de nuestras implicaciones personales en el proceso y asumimos que ningún investigador analizaría el contenido de las novelas de un modo idéntico a otro.

El método que hemos empleado para la reducción y el análisis de los datos ha sido el análisis del contenido. Basoredo (2010) lo define como un estudio minucioso y sistemático de un texto con el objeto de acceder a su significado e interpretarlo. Ello, a través del procesamiento de la información, categorizando sus elementos y poniendo de relieve las relaciones existentes entre estos. Las categorías establecidas ayudan a reducir y clasificar la información y, por consiguiente, a la interpretación.

Gil Flores (1994) propone un proceso general de análisis de datos cualitativos que nos ha servido de orientación. Este proceso consta de la reducción de datos, en primera instancia, la disposición de los mismos, a continuación, y la obtención y verificación de conclusiones, para acabar. Partiendo de una lectura global, que sirve para una primera identificación de temas y relaciones, en la reducción de datos estos se dividen en unidades que se consideran relevantes o significativas siguiendo un criterio temático y se agrupan o clasifican esas unidades en categorías de contenido (que representan conceptos, temas o ideas). La disposición de los datos hace referencia a la presentación de la información simplificada y organizada para extraer conclusiones en tablas que incluyen, en nuestro caso, fragmentos de las novelas. La obtención de conclusiones se centra fundamentalmente en la realización de interpretaciones, la identificación de regularidades y el establecimiento de relaciones entre los datos considerando la preocupación de partida, sintetizando y ordenando la información recabada de tal manera que permita iluminar el problema.

\subsection{Resultados y discusión}

Tras la lectura de las obras señaladas realizamos una selección de fragmentos textuales que consideramos por su contenido más directamente relacionados con la construcción de identidades de género, centrando el análisis en los mismos, e identificamos dos núcleos temáticos (que establecemos como categorías) que nos parecen destacables de acuerdo con nuestro objetivo de investigación, y que hemos podido agrupar, a su vez, en distintas subcategorías, que se corresponden con diferentes subtemas. A continuación, presentamos tales categorías y subcategorías y las definimos a partir de algunos fragmentos representativos. Por motivos de extensión reproducimos ejemplos muy breves y únicamente de algunas de las subcategorías.

Tabla 1 


\section{Categoría 1, subcategoría 1.1.}

\section{Categoría 1) Cuestionamiento de la asociación de un supuesto modelo de mujer} occidental a la autonomía o la liberación y de un supuesto modelo de mujer marroquí a la sumisión

1.1. Dificultades en el ejercicio de la libertad ante la definición del propio modelo de género de mujeres de origen marroquí en sociedades occidentales

\section{Tabla 2}

Categoría 1, subcategoría 1.2.

Categoría 1) Cuestionamiento de la asociación de un supuesto modelo de mujer occidental a la autonomía o la liberación y de un supuesto modelo de mujer marroquí a la sumisión

1.2. Cuestionamiento de la supuesta liberación de las mujeres occidentales

\begin{tabular}{l|l}
\hline 1.2 .1$. Ocupación múltiple & 1.2.2. Cánones de belleza
\end{tabular}

La definición de la primera categoría se desprende de la lectura de fragmentos que nos conducen a cuestionarnos la asociación simplista a menudo realizada entre un supuesto modelo de mujer occidental y la liberación y la autonomía y un supuesto modelo de mujer de origen marroquí y la sumisión. Este cuestionamiento se produce cuando, o bien se evidencian en la obra las dificultades de las mujeres de origen marroquí ante el ejercicio de la defendida autonomía en la construcción de su identidad de género, o bien se ponen de manifiesto aspectos tales como las múltiples ocupaciones de las mujeres occidentales en la actualidad (que, en jornadas interminables, desempeñan tanto los roles tradicionales relacionados con las tareas domésticas o la maternidad como los asociados a la emancipación, como puedan ser la formación superior o la creación artística, además del trabajo fuera de casa) o los cánones de belleza, que pueden también leerse como otra forma de subordinación.

Ejemplo de la categoría 1.1.:

Me alegra oír que vuestras mujeres tienen ganas de formarse, y yo te pido que las convenzas para que se inscriban en los cursos de la escuela de idiomas y en los de la escuela de adultos, donde las atenderán encantados. Lo que de ninguna forma será posible es abrir grupos específicos para ellas, porque eso choca directamente contra nuestros valores culturales; para nosotros es imprescindible que hombres y mujeres vivan en igualdad de condiciones, y no podemos renunciar a este rasgo fundamental de nuestra manera de entender el mundo (El Hachmi, 2015: 125-126).

Ejemplo de la categoría 1.2.1:

No era la primera dona que coneixia que es passava el dia fent feina a casa i després les nits a la fàbrica. Una bogeria, és clar, la hipoteca, les lletres del cotxe, ja se sap que s'ha de lluitar molt en els temps que estem. Les dones alliberades, és clar, valen per deu. ¿Qui vol una dona submissa que es queda a casa cuidant els nens i fent pans 
de pessic mentre mira la telenovel·la de la primera si es pot tenir una superwoman que s'encarregui de tot?

Des de que havia entrat en aquella fàbrica, el model occidental d'emancipació femenina era una decepció darrere l’altra (El Hachmi, 2008a: 161-162).

\section{Tabla 3}

Categoría 2, subcategoría 2.1.

Categoría 2) El desarrollo de un modelo de género basado en una conquista gradual de autonomía

2.1. Estímulo de autonomía

\begin{tabular}{l|l|l|l|l|l|l}
\hline $\begin{array}{l}2.1 .1 . \\
\text { Insumisión, } \\
\text { fortaleza }\end{array}$ & $\begin{array}{l}2.1 .2 . \\
\text { Independencia, } \\
\text { individualidad }\end{array}$ & $\begin{array}{l}2.1 .3 . \\
\text { Desarrollo } \\
\text { de sueños y } \\
\text { talentos que } \\
\text { sirven de } \\
\text { orientación }\end{array}$ & $\begin{array}{l}\text { Formación y } \\
\text { participación en } \\
\text { la }\end{array}$ & $\begin{array}{l}2.1 .5 . \\
\text { Ejercicio } \\
\text { de } \\
\text { del mundormación }\end{array}$ & $\begin{array}{l}\text { 2.1.6. } \\
\text { Libertad }\end{array}$ & $\begin{array}{l}\text { 2.1.7. } \\
\text { Combinación } \\
\text { de los puntos } \\
\text { anteriores }\end{array}$ \\
& & & & \\
\end{tabular}

La definición de la segunda categoría se deriva de la apreciación, tras la lectura completa de las obras, del desarrollo gradual de la conquista de esa autonomía defendida por parte de las protagonistas. Hemos podido comprobar que la autonomía en la construcción de un determinado modelo de género no solo se manifiesta sino que previamente es estimulada, se gesta y se desea, para acabar siendo expresada. Todo ese proceso, a nuestro entender, merece ser puesto de relieve, ya que tras decisiones que aparentemente no relacionaríamos con un modelo de mujer autónoma subyacen procesos de reflexión que desmontan la hipótesis de la ignorancia de esas mujeres supuestamente sumisas. Pero detengámonos por separado en las distintas fases del proceso de conquista de la autonomía en la construcción de la identidad de género.

Cuando exponemos que la autonomía “se estimula” hacemos alusión a los modelos representados por mujeres mayores que las protagonistas o a las expectativas que estas depositan sobre las mismas, ya que, a través de sus palabras, de manera explícita o recurriendo a la narración de relatos y al empleo de analogías y metáforas, las incitan a la insumisión y al desarrollo de un carácter fuerte; al cultivo de su independencia y de su individualidad; al desarrollo de sus sueños y de los talentos que sostienen que toda mujer posee pese a que pueda no haber descubierto; a la dedicación a una formación que les posibilitará participar en la transformación del mundo; así como al ejercicio o la lucha por la conquista de sus derechos y libertades.

Ejemplo de la categoría 2.1.1.:

Mina decía que cuando estás atrapado siempre tienes la posibilidad de complacer al monstruo bajando la vista y llorando, o sorprenderlo mirando hacia arriba [...] Si [...] quieres asombrar al monstruo, clava la mirada en lo alto, en aquel trocito de cielo [...] Entonces, el torturador que te vigila desde arriba verá tus ojos y se asustará [...] Ya sabes todo lo esencial, que por pequeña que sea una niña tiene energía suficiente para desafiar a los torturadores, para ser valerosa y paciente y no perder el tiempo temblando y gritando (Mernissi, 2013: 211-213). 
Ejemplo de la categoría 2.1.3.:

- Las madres deberían explicar a las niñas [...] la importancia de los sueños -decía tía Habiba-. Proporcionan un sentido de orientación. No basta con rechazar este patio, necesitas tener una idea de las vegas con que quieres reemplazarlo [...] Me dijo también que por el momento no debía preocuparme, porque pertenecía a un largo linaje de mujeres con sueños vigorosos [...] Tu madre tiene alas dentro, también [...] Serás capaz de transformar a la gente, estoy segura. Yo en tu lugar no me preocuparía (Mernissi, 2013: 263-264).

\section{Tabla 4}

Categoría 2, subcategoría 2.2.

Categoría 2) El desarrollo de un modelo de género basado en una conquista gradual de autonomía

\begin{tabular}{|c|c|c|c|c|}
\hline \multicolumn{5}{|c|}{ 2.2. Gestación de autonomía } \\
\hline 2.2 .1$. & 2.2 .2 & 2.2.3. & 2.2 .4 & 2.2.5. \\
\hline Autoengaño & $\begin{array}{l}\text { Influencia de } \\
\text { opiniones ajenas }\end{array}$ & $\begin{array}{l}\text { Complejidad de } \\
\text { decisiones o toma } \\
\text { de postura (a } \\
\text { través de las que } \\
\text { la protagonista } \\
\text { define quién es) }\end{array}$ & $\begin{array}{l}\text { Identificación } \\
\text { práctica de la } \\
\text { lectura e } \\
\text { imposibilidad de } \\
\text { conformismo } \\
\text { (por oposición a } \\
\text { una asunción } \\
\text { acrítica y feliz de } \\
\text { un modelo de } \\
\text { sumisión) }\end{array}$ & $\begin{array}{l}\text { Combinación } \\
\text { de los puntos } \\
\text { anteriores }\end{array}$ \\
\hline
\end{tabular}

Nos referimos a la "gestación" de la autonomía para ilustrar de qué manera, tras la toma de decisiones que aparentemente relacionaríamos con un modelo de sumisión, a menudo subyacen ricos procesos reflexivos, ejercicios conscientes de autoengaño, la consideración y valoración de opiniones ajenas o el reconocimiento por parte de las protagonistas de que la lectura o la formación dificultan en gran medida el conformismo con un modelo de vida o de mujer asumido para contentar a otros, en situaciones en las que estas aún no se resuelven a tomar la palabra o a actuar de acuerdo con su propio criterio y voluntad, pero tras las que en ningún caso se esconde la ignorancia. Y esos procesos reflexivos que diferenciamos en las distintas subcategorías dentro de la “gestación de autonomía”, a nuestro entender, constituyen un paso ineludible ante su conquista. Antes de manifestar un comportamiento autónomo las personas nos enfrentamos a las numerosas contradicciones, influencias y complejidades que entraña toda toma de decisión y si esto se traduce en un proceso de reflexión tan rico como los que ejemplifican los textos trabajados, consideraríamos desacertado identificar sin más tal ejercicio de reflexión con la ignorancia y la sumisión de las mujeres de origen marroquí, haciendo una lectura de sus decisiones que oculta la enorme complejidad y los procesos de pensamiento subyacentes. 
Ejemplo de la categoría 2.2.1:

Nadie me ha pedido que deje de leer, mi madre se conforma con que haya decidido volver la mirada hacia nuestra tierra y me case con un buen chico de allí. Y es tan bueno, mi primo, el hijo de su hermano. A Driss lo ha querido mucho desde que nació, le ha hecho regalos y le ha pagado fiestas. Ahora también le regala a su hija, su bien más preciado. Pero intento no ver así las cosas y recordarme a mí misma que fui yo quien decidió aceptar su propuesta, que ella me dijo que si no me parecía bien lo entendería. Trato de recordar que, cuando yo me case, ella será libre y todo será más fácil (El Hachmi, 2015: 77-78).

Ejemplo de la categoría 2.2.4:

No dejaba de pensar que qué mierda que yo no pueda ser como las otras mujeres, conformarme y ser feliz con lo que tengo; seguro que el defecto es mío. La principal diferencia entre las mujeres que se acostumbran al destino que les ha tocado vivir, que se sienten cómodas en su vida matrimonial y no protestan si no es en voz baja con sus amigas, y yo, es que ellas no han leído y yo sí; y, al lado del cuerpo ya dormido de mi marido-primo, entiendo que, a pesar de mis esfuerzos por dejar atrás mi vida anterior, sigo sin poder pensar como una analfabeta (El Hachmi, 2015: 197).

\section{Tabla 5}

Categoría 2, subcategoría 2.3.

$\begin{aligned} & \text { Categoría 2) El desarrollo de un modelo de género basado en una conquista gradual de } \\
& \text { autonomía }\end{aligned}$
\begin{tabular}{l|l|l|l|l} 
2.3. Deseo de autonomía & $\begin{array}{l}2.3 .3 . \\
\text { Sueños y } \\
\text { 2.3.1. } \\
\begin{array}{l}\text { Deseo de } \\
\text { transgresión de } \\
\text { fronteras }\end{array}\end{array}$ & $\begin{array}{l}\text { Deseo de } \\
\text { independencia } \\
\text { y de } \\
\text { anonimato }\end{array}$ & $\begin{array}{l}\text { Deseo de } \\
\text { trazar el propio } \\
\text { posibilidades } \\
\text { camino }\end{array}$ & $\begin{array}{l}\text { Combinación } \\
\text { de los puntos } \\
\text { anteriores }\end{array}$ \\
\end{tabular}

Cuando hablamos de “deseo de autonomía” hacemos alusión a la expresión por parte de las protagonistas de su voluntad de transgredir distintos tipos de fronteras impuestas, de ser independientes, de sumirse en el anonimato para poder escapar de influencias y opiniones externas que intervienen en la toma de decisiones que marcan el curso de sus vidas, de ampliar sus posibilidades de ser o de trazar el propio camino.

Ejemplo de la categoría 2.3.1:

Oh, sí, tía Habiba -pensaba yo-, seré una hechicera. Atravesaré la vida estrictamente codificada que me aguarda en las estrechas calles de la Medina, con la mirada fija en el sueño. Me deslizaré por la adolescencia, estrechando la fuga [...] Acariciaré las palabras. Las cultivaré para iluminar las noches. Derribar los muros y achicar las puertas [...] Cincelaré palabras para compartir el sueño y demostrar la inutilidad de las fronteras (Mernissi, 2013: 140-141).

Ejemplo de la categoría 2.3.2.: 
Ella lograba combinar dos papeles en apariencia contradictorios: bailar con un grupo y mantener el ritmo propio peculiar. Yo deseaba bailar como ella, con la comunidad y también con mi propia música interior, procedente de una profunda fuente interior secreta y más fuerte que los tambores. Más fuerte y sin embargo más suave y liberadora (Mernissi, 2013: 199-200).

\section{Tabla 6}

Categoría 2, subcategoría 2.4.

Categoría 2) El desarrollo de un modelo de género basado en una conquista gradual de autonomía

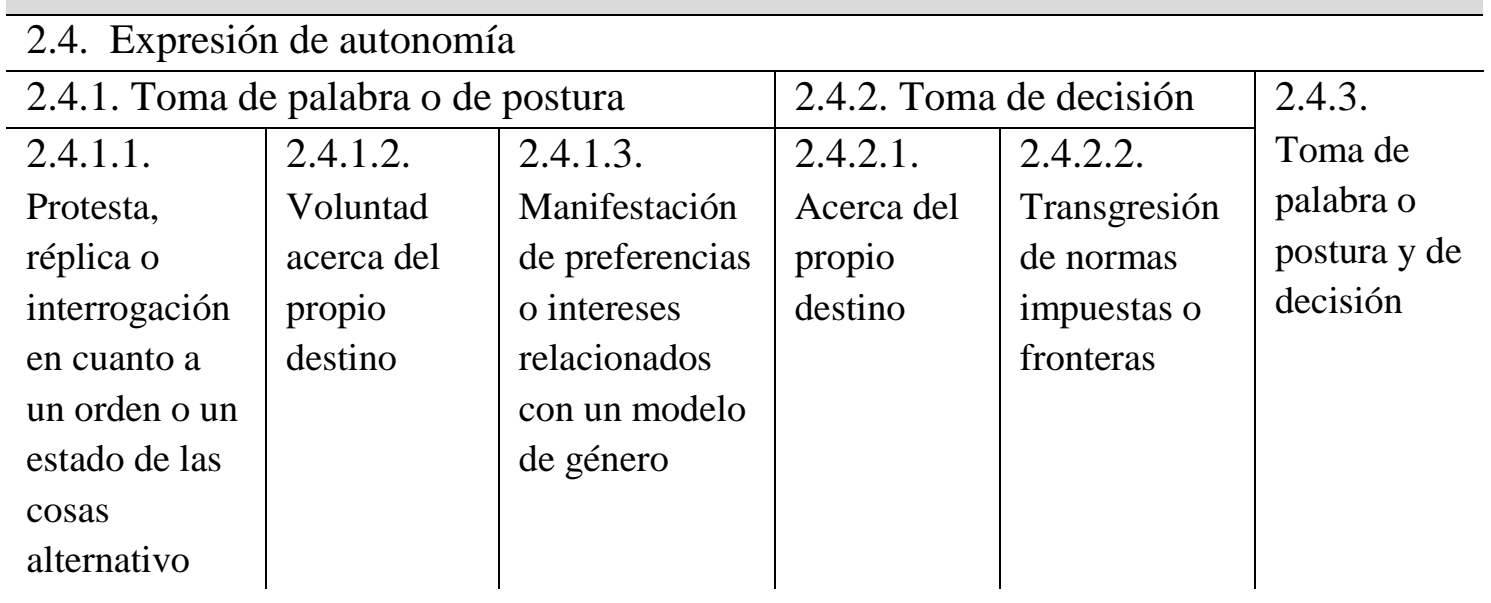

Por último, la "expresión de autonomía” se corresponde con una toma de postura o de palabra explícita por parte de las protagonistas, ya sea a modo de protesta, de réplica o interrogándose al respecto de la posibilidad de un orden social alternativo, que no las relegue a una condición de subordinadas; evidenciando su voluntad acerca del propio destino; o manifestando preferencias o intereses relacionados con un determinado modelo de género, que no se corresponde precisamente con el de la mujer dedicada en exclusiva a las tareas domésticas. También puede mostrarse en forma de una toma de decisión al respecto del propio destino o que implica la transgresión de determinadas normas o fronteras impuestas. Y, en otras ocasiones, se conjugan ambas posibilidades, una toma de postura y de palabra con la consiguiente toma de decisión y la actuación de la protagonista.

Ejemplo de la categoría 2.4.2.1.:

Fue entonces cuando empecé a pensar que el destino me lo tenía que hacer yo y que quizá era hora de dejar de recorrer meandros. Fue entonces cuando tomé la decisión que lo precipitaría todo.

Me voy. Si eso es lo que quieres. No, no es lo que quiero, pero no le veo ningún sentido a todo esto. Mi pequeño apartamento-cocina-comedor me esperaba en aquella planta baja acabada de construir, todo equipado, todo bien limpio y bonito. Y yo me senté en el sofá cama y me quedé allí, delante del televisor apagado, reflejándome en la pantalla, las piernas abiertas y estiradas. Las chicas decentes no se sientan así, hija. Y yo que a partir de entonces me sentaría como quisiera y 
estudiaría lo que quisiera. Sólo eso. Aquel día no hice nada más, pero eso era la libertad. Decidir, decidir y decidir (El Hachmi, 2008b: 329-335).

$\mathrm{Al}$ respecto de esta segunda categoría quisiéramos destacar que en este trabajo defendemos que si lo que nos proponemos es analizar los procesos de construcción de identidades de género, no podemos obviar las fases que han precedido a estos ejercicios de expresión de autonomía por parte de las protagonistas en forma de una toma de postura, manifestaciones finales para entender cómo se desarrollan los aludidos procesos.

\section{CONCLUSIONES Y POSIBILIDADES DE EXPLOTACIÓN DIDÁCTICA}

Este trabajo partía de la detección de dos problemas fundamentales en la construcción de las identidades de género por parte del alumnado de Educación Secundaria. En primer lugar, remitiendo a estudios precedentes, nos hacíamos eco de la ausencia de mujeres referentes de realización intelectual en los manuales de Educación Secundaria, así como de la exclusión o la menor presencia de estas en los cánones literarios, lo que les resta relevancia social y autoridad y priva a las alumnas de modelos de identificación. En segundo lugar, la representación distorsionada, tan ampliamente extendida, que hace corresponder en el imaginario colectivo la imagen de las mujeres de origen marroquí con un modelo de género basado en la sumisión y en la ignorancia, que nos proponíamos desmontar porque no se ajusta a la realidad y porque, además, perjudica las relaciones interculturales entre comunidades que hoy conviven en nuestras sociedades.

Nuestro propósito de favorecer la autonomía en la construcción de las identidades de género se sustentaba en una idea básica que forma parte de la definición de este concepto: las categorías de género son construcciones socioculturales, por lo que no se sostiene la autoridad de normativa alguna para prescribir significados, valores, pautas de conducta, ámbitos o espacios asociados a una determinada categoría de género, como a lo largo de la historia ha ocurrido con las mujeres.

Para proporcionar al alumnado de Educación Secundaria modelos de mujer que sirvan de ejemplo de realización intelectual, que puedan incluirse como voces literarias a nuestro corpus textual por su calidad estética y que contribuyan, al tiempo, a desmontar esa imagen distorsionada de las mujeres de origen marroquí, nos decantamos por la lectura de algunas obras de Fatema Mernissi y Najat el Hachmi. Tras el análisis hemos constatado la potencialidad de las mismas para: (1) cuestionar la asociación superficial de la que hemos construido como "alteridad cultural" (las personas de origen marroquí) a un modelo de género que llenamos de significados despectivos (sumisión, ignorancia) y del "nosotros" en el que nos identificamos (occidentales) a un modelo de género al que, por contraposición, atribuimos significados positivos (autonomía, liberación); y (2) comprender cómo la autonomía en la construcción de las identidades de género es una conquista gradual que se desarrolla a lo largo de todo un proceso que nos parece que merece ser observado con detenimiento y puesto en valor, en la medida en que la toma de consciencia al respecto de ese proceso desmonta la tan extendida hipótesis de la 
ignorancia de las mujeres de origen marroquí, y creemos que puede inspirar esa misma conquista gradual de autonomía por parte de nuestras alumnas. Reconocidas estas potencialidades, si bien en este trabajo nos hayamos centrado en el análisis del contenido de las obras y no ahondemos en las posibilidades de explotación didáctica, concluimos que pueden ser muy apropiadas para su inclusión en el corpus textual y para su trabajo en la etapa de Educación Secundaria.

Consideramos que la opción más fértil sería plantear una experiencia de club de lectura a partir de las mismas tras la lectura completa de las obras por parte de alumnado de primero o segundo ciclo de Educación Secundaria, y centrando la reflexión y el intercambio de ideas en las reuniones en aquellos fragmentos (más largos que los que aquí hemos reproducido por motivos de extensión) que en nuestro análisis hemos comprobado que se relacionan directamente con nuestros objetivos. Considerando el volumen de fragmentos textuales con autonomía de significado que hemos reunido para ilustrar las ideas recogidas en cada una de las categorías, podríamos organizar el club de lectura en cinco sesiones de una hora de duración. El docente de Lengua y Literatura guiaría las sesiones teniendo presentes, además del objetivo fundamental de desarrollar el gusto por la lectura y de favorecer la comprensión, los objetivos específicos de este trabajo. Y esta propuesta podría complementarse con un ejercicio de investigación por parte de los discentes sobre la obra literaria y la cultura de origen de las autoras, elaborando en pequeños grupos un dossier con los conocimientos proporcionados por la lectura de los sucesivos capítulos y la búsqueda de información adicional.

Recordemos que el escenario de la educación literaria contemporánea coincide en la conveniencia de conceder un papel eminentemente activo al receptor. En consecuencia, se ha dirigido una atención especial a prácticas como la discusión literaria, que permite enfatizar la lectura interpretativa (una lectura que demanda estrategias lectoras de alto nivel y la disposición de conocimientos enciclopédicos y culturales) a través de una construcción compartida de significado. Así, diversos autores coinciden al presentar la discusión literaria como una opción muy adecuada para avanzar en la comprensión de textos literarios desde el plano literal hacia los planos inferencial e interpretativo, desembocando en una lectura más rica, profunda y crítica. Y es que los también llamados círculos literarios o clubes de lectura posibilitan tanto la construcción colectiva de sentido, como la apropiación personal y afectiva de los textos, gracias a la figura de un mediador que facilita la discusión y guía la comprensión y al contraste de una diversidad de puntos de vista aportados por los participantes (Bellorín y Reyes, 2012; Colomer, 2012; Correro, 2012; Gil Juan, 2012; Margallo, 2012; Munita y Manresa, 2012; Rincón, 2012).

\section{REFERENCiAS BIBLIOGRÁFICAS}

Basoredo, C. (2010). Herramientas de análisis de contenido, de utilidad en los ámbitos del aprendizaje y la evaluación. Quaderns digitals: Revista de Nuevas Tecnologías y Sociedad, 61, 1-35. 
Bellorín, B. y Reyes, L. (2012). Álbumes en marcha: recuento de proyectos de aula en torno a las narrativas visuales. En La literatura que acoge: inmigración y lectura de álbumes, T. Colomer y M. Fittipaldi (coords.), 172-196. Barcelona: Banco del Libro-Gretel.

Bueno, J. (2009). Perspectivas de género en la Europa multicultural: escritoras mujeres magrebíes en Francia. En Matrias, patrias. Identidades genéricas traspasando fronteras, M. Palma (coord.), 27-45. Madrid: Entimema.

Butler, J. (2006). Deshacer el género. Barcelona: Paidós. (2010). El género en disputa. El feminismo y la subversión de la identidad. Barcelona: Paidós.

Carro, S., Barbé i Serra, A. y Vidal, C. (2014). La construcción de las identidades de género: actividades para trabajar con jóvenes y adolescentes. Madrid: Catarata.

Colomer, T. (2012). Las discusiones infantiles sobre álbumes ilustrados. En La literatura que acoge: inmigración y lectura de álbumes, T. Colomer y M. Fittipaldi (coords.), 87-118. Barcelona: Banco del Libro-Gretel.

Correro, C. (2012). Experiencias literarias en contextos de inmigración: textos sin pretextos. En La literatura que acoge: inmigración y lectura de álbumes, T. Colomer y M. Fittipaldi (coords.), 251-262. Barcelona: Banco del Libro-Gretel.

El Hachmi, N. (2008a). Jo també sóc catalana. Barcelona: Columna. (2008b). El último patriarca. Barcelona: Planeta. (2015). La hija extranjera. Barcelona: Destino.

García, A. et al. (2011). Velos, burkas... moros: estereotipos y exclusión de la comunidad musulmana desde una perspectiva de género. Investigaciones feministas, 2, 283298.

Gil Flores, J. (1994). Análisis de datos cualitativos: aplicaciones a la investigación educativa. Barcelona: PPU.

Gil Juan, M. R. (2012). Álbumes que versionan y acogen: nuevas oportunidades para los clásicos de siempre”. En La literatura que acoge: inmigración y lectura de álbumes, T. Colomer y M. Fittipaldi (coords.), 206-212. Barcelona: Banco del Libro-Gretel.

Gimeno Sacristán, J. (1989). Planificación de la investigación educativa y su impacto en la realidad. En La enseñanza: su teoría y su práctica, J. Gimeno Sacristán y A. Pérez Gómez (coords.), 166-187. Madrid: Akal.

López-Navajas, A. (2012). Análisis de la ausencia de las mujeres en los manuales de la ESO: una genealogía de conocimiento ocultada. Revista de Educación, 363, 282308.

(2014). Las escritoras ausentes en los manuales: propuestas para su inclusión. Didáctica. Lengua y Literatura, 26, 217-240.

López-Navajas, A. y López García-Molins, A. (2012). El desconocimiento de la tradición literaria femenina y su repercusión en la falta de autoridad social de las mujeres. En Las mujeres, la escritura y el poder, J. Benavent, E. Moltó Hernández y S. FabrizioCosta (eds.), 27-40. Valencia: Universitat de València. 
Margallo, A. M. (2012). Qué literatura para los recién llegados. En La literatura que acoge: inmigración y lectura de álbumes, T. Colomer y M. Fittipaldi (coords.), 144171. Barcelona: Banco del Libro-Gretel.

Martínez-León, P., Ballester-Roca, J. e Ibarra Rius, N. (2017). Identidades fronterizas y pertenencias plurales: diversidad e interculturalidad a través de la educación literaria. Didáctica. Lengua y Literatura, 29, 155-172.

Mernissi, F. (1991). Marruecos a través de sus mujeres. Madrid: Ediciones de Oriente y del Mediterráneo.

(1995). El poder olvidado. Las mujeres ante un islam en cambio. Barcelona: IcariaAntrazyt. (2013). Sueños en el umbral. Barcelona: Debolsillo.

Munita, F. y Manresa, M. (2012). La mediación en la discusión literaria. En La literatura que acoge: inmigración y lectura de álbumes, T. Colomer y M. Fittipaldi (coords.), 119-143. Barcelona: Banco del Libro-Gretel.

Nash, M. (2001). Diversidad, multiculturalismos e identidades: perspectivas de género. En Multiculturalismos y género: un estudio interdisciplinar, M. Nash y D. Marre (eds.), 21-47. Barcelona: Bellaterra.

Ramírez, E. (1996). Inmigrantes en España: vidas y experiencias. Madrid: CIS.

Rincón, A. (2012). De la imagen a la palabra. Conversaciones literarias en el aula de acogida. En La literatura que acoge: inmigración y lectura de álbumes, T. Colomer y M. Fittipaldi (coords.), 197-205. Barcelona: Banco del Libro-Gretel.

Segarra, M. (1998). Mujeres magrebíes: la voz y la mirada en la literatura norteafricana. Barcelona: Icaria-Antrazyt.

Soriano, R. y Santos, C. (2002). El perfil social de la mujer inmigrante marroquí en España y su incidencia en la relación intercultural. Papeles de Geografía, 36, 171184. 